\title{
Research on Vocational College Students' Internship Quality Evaluation-Take students in the specialty of architectural engineering technology as an example
}

\author{
Xiaomei Su \\ Wuhan City Vocational College, Wuhan, 430064, China
}

Keywords: Vocational college; Specialty of architectural engineering technology; Internship quality evaluation

\begin{abstract}
In current internship quality evaluation of vocational college students, there often exist some problems such as insufficient effectiveness of internship evaluation, and single way of internship evaluation, thus it is required to enhance the management and control on whole process of internship from different aspects so as to improve vocational college students' internship quality. This paper takes students in the specialty of architectural engineering technology as an example to analyze the current situation of vocational college students' internship quality evaluation, and proposes countermeasures to improve the quality of internship quality evaluation for vocational college students in the specialty of architectural engineering technology.
\end{abstract}

\section{Introduction}

The talents cultivated in specialty of architectural engineering technology in vocational colleges are high-quality technology and skill-based talents who have the ability of construction technology and site management. It can be said that the graduation practice is one of indispensable important practice teaching links in training plan of professional architectural engineering technology talents, and also the indispensable basic training content in cultivating high-quality technology and skill-based talents. Through graduation practice, it is able to further cultivate vocational college students' ability of practical knowledge application, analyzing and solving problems, adapting to the society, and competitive strength in employment; the graduation practice is an important means which promotes mutual combination of vocational college classroom teaching and social practice, and also a kind of indispensable transition for vocational college students to step into the society from vocational colleges. The students' internship quality evaluation will directly affect whether the training objective of professional architectural engineering technology talents can be realized and then influence students' personal development, thus it is very critical to enhance the vocational college students' internship quality evaluation. Then, this paper will takes the students in the specialty of architectural engineering technology as an example to carry out research.

\section{Analysis on current situation of internship quality evaluation of vocational college students in the specialty of architectural engineering technology}

The internship quality evaluation is one of very important contents in vocational college students' internship. Currently, most of vocational colleges have dissatisfactory result in internship quality evaluation. The main reason is that the internship assessment and evaluation system of vocational colleges is not perfect, there exists result-oriented evaluation and lacks of effective process evaluation, which causes the situation that the evaluation completely becomes a mere formality and lacks of sufficient objectivity.

Firstly, the insufficient internship management results in insufficient effectiveness of students' internship quality evaluation. In vocational college students' internship, the dead zone to which the insufficient attention is paid on internship management, and the partial vocational college students' practice work is even equal to sheep-herding management; after the vocational colleges contact the internship posts for students, the students' internship management is fully handled by the enterprises. 
The vocational colleges lack of sufficient knowledge of students' internship situation, thus they can't provide students with corresponding guidance and it is nature that they can't guarantee the effect of internship.

Secondly, the single evaluation form results in low participation of enterprises. Currently, the students' internship evaluation in partial vocational colleges mainly includes internship result evaluation, internship document evaluation, and internship process evaluation. As for weighting of practice defense, different vocational colleges have different standards. The internship result of specialty of architectural engineering technology includes the internship drawing and internship paper, the internship documents include internship diary, internship report, recommendation form of internship, and security protocol, etc., the process evaluation includes teachers' evaluation on students, teacher-student close degree, overall completion condition of internship task, and other comprehensive evaluation, and the practice defense is organized and developed by vocational colleges after students complete their internship and then independently evaluated. The above specific weighting shall be determined by practice supervisors according to their experience.

Thirdly, the evaluation is not quantized and just depends on experience, thus the one-sidedness will inevitably happen. The practice supervisors generally carry out evaluation according to their intuitive impression but give no quantization, thus the one-sided evaluation will naturally appear.

\section{Countermeasures of improving the quality of internship quality evaluation on students in the specialty of architectural engineering technology of vocational colleges}

\section{To properly arrange students' internship time}

Currently, there is often time conflict between the graduation practice arrangement for vocational college students in the specialty of architectural engineering technology and job-hunting and postgraduate entrance exam, which causes the reduction of some students' subjective initiative in participating in internship and then influences the normal implementation of students' internship activity. Meanwhile, due to short internship, the students can't get a comprehensive understanding of professional knowledge of architectural engineering technology. Due to this reason, it is able to carry out effective adjustment on specific time of graduation practice, and reasonably lengthen the students' practice time; the author suggests that the students' practice time can start since the 5th semester. In terms of organization and arrangement of specific teaching plan, the theoretical course learning and assessment in the 5th semester shall be completed in the first 15 weeks as much as possible. In this way, while the vocational college students enter into the later period of the 5th semester, they can enter into graduation practice. The graduation practice shall include the 5th and 6th semester. On this basis, it is required to actively encourage the students in the specialty of architectural engineering technology to fully utilize the winter vacation to actively participate in the internship so as to lengthen students' graduation practice time. In this way, the effectiveness of internship arrangement for vocational college students in the specialty of architectural engineering technology is greatly improved, and the vocational college students can have more time to devote themselves into enterprise internship, thus they can contact the society as soon as possible and fully practice their working ability.

\section{To formulate and implement diversified evaluation mechanism}

In the process of performance evaluation on vocational college students in the specialty of architectural engineering technology, it is required to list vocational college students' actual skills, professional ethics, professional quality, labor discipline and other contents into important evaluation indexes, combine with human resource management rules of practice enterprises into internship quality evaluation mechanism for vocational college students in the specialty of architectural engineering technology, show students in true occupational environment, realize the full integration of vocational college students' mutual evaluation, teachers' evaluation, and enterprise evaluation, and truly show the diversified and open evaluation for vocational college students' internship. As for unqualified intern students through evaluation, it is required to strictly implement the rules and grant no graduation. 


\section{To fully explore various kinds of internship evaluation ways}

Currently, the internship of vocational college students in the specialty of architectural engineering technology mainly include centralized internship and distributed internship. The advantage of the former is easy management, and the disadvantage is high internship expenditure; furthermore, the centralized internship pays attention to generality, thus restricting students to exert their ability and resulting in the situation that the vocational college students are always under passive internship and can't select internship enterprise and internship post based on their job hobby; therefore, this form is rarely adopted at present. The latter conforms to the teaching environment of vocational college students' internship. The vocational college students in the specialty of architectural engineering technology can contact the internship according to the employment direction they are interested in. This way of internship can greatly help vocational college students to develop their personalization, thus greatly reducing vocational college students' pressure in contacting the internship enterprise; besides, the internship units can be established in internship to implement comprehensive, deep, and detailed investigation on intern students' various abilities so as to improve the accuracy and success ratio in promoting and selecting high-quality talents. The vocational college students can have the chance to directly enter into front-line production to take practice, and participate in specific production process of enterprises, which will greatly help them to quickly be familiar with actual work after graduation. It can be seen that the distributed internship is very helpful to internship enterprises and vocational college students, and it has become an important way of internship for vocational college students in the specialty of architectural engineering technology.

However, due to various reasons, some vocational college students are still unwilling to participate in the internship, and some students even can't contact internship enterprises which are suitable for themselves due to introverted personality. As for those students, we can apply the way of simulated internship to carry out internship. The so-called way of simulated internship mainly refers to contacting and collecting the specific engineering example which can reflect internship content of specialty of architectural engineering technology and recording them according to the internship requirement of specialty of architectural engineering technology in vocational colleges. While the above content is recorded, it is able to arrange some internship supervisors with rich experience to give instruction; the contents, especially implicit content, can be intuitively shown before learners through image technology; in this way, it is able to bring the feeling of being personally on the scene to the learners. Through utilization of image data, the vocational college students can get a comprehensive understanding of internship content, and then the colleges can utilize their internship resources to bring students to cooperated internship enterprises to take an internship so as to improve their actual operation ability; in this way, the actual ability of vocational college students in the specialty of architectural engineering technology can be well cultivated.

\section{To enhance the construction of vocational college internship base}

The vocational colleges shall take mutual benefit and joint development of school and enterprise as basic principle, actively and reliably select a batch of architectural construction, architectural design, and architectural supervision enterprises with good credit standing and carry out cooperation with them to create stable vocational college students' internship base. The vocational colleges shall fully exert their advantages, utilize scientific and technological service, enterprise on-duty employee training, technology consulting and other forms to eliminate difficulties for the enterprises and motivate the subjective initiative of enterprises to accept intern students. After the vocational college students come to internship base, the enterprises shall follow school-enterprise cooperation agreement to let learners learn the operation skills of architectural engineering technology so that the students can combine the theoretical knowledge learnt in the classroom with practical skills and realize true mastery. The internship bases of vocational colleges shall practically arrange professional technical personnel with powerful technical strength to serve as the part-time supervisors of vocational college intern students, instruct architectural engineering technology, and implement strict management. 


\section{To introduce internship tutorial system}

It is able to attempt to introduce tutorial system in the internship process of vocational college students in specialty of architectural engineering technology. In the last semester, the vocational college teachers can disclose the research direction to their students, and then the students and teachers jointly carry out two-way selection to specify the relationship. The tutors shall implement overall guidance on the graduation practice situation of students they guide according to specific requirement of internship teaching. Certainly, the tutors shall let vocational college students know the site operation of architectural engineering technology in advance according to their own working experience, which is greatly helpful for vocational college students to enter into working state in advance. Besides, the tutors can utilize the social resource they master to recommend their students to take internship in suitable unit in a targeted and planned way according to vocational college students' professional direction.

\section{To promote overall-process management on students' internship}

In the internship management for vocational college students in the specialty of architectural engineering technology, it is required to realize the overall-process management on students' internship from following perspectives.

Firstly, it is required to form perfect teaching plan and program for internship of students in the specialty of architectural engineering technology, carry out specific and clear stipulations for the internship time, content, teaching materials, and way of evaluation so as to further standardize the vocational college students' internship. Before the students take internship, the motivation shall be made to guide the students to be aware of urgency and importance of internship, and improve students' subjective initiative to participate in internship. In the internship process, the standard internship monitoring mechanism shall be formed. The reason why the overall-process monitoring is implemented for vocational college students' internship is to ensure good quality of internship. The internship supervisors shall require students to carry out regular contact through network, telephone, short message, or other ways; once the students meet some problems, they can consult to the teachers at any time. Meanwhile, the teachers shall also carry out checking on learners' internship effect on a regular basis so as to timely find and solve relevant problems incurred in the internship.

Secondly, it is required to further implement the specific evaluation method of vocational college students' internship; strictly formulate the evaluation process on internship in the specialty of architectural engineering technology, and divide the evaluation into four parts, that is, daily performance link, practice diary link, practice summary link, and practice defense link. The daily performance includes whether the vocational college students are obedient to the management of the school and internship enterprise, whether they abide by various rules of the school and internship enterprise, whether they report their internship condition to internship supervisors on a regular basis, and whether students' performance evaluation is made by internship supervisors and internship enterprises through assessment. The practice diary and practice summary is one of important contents in vocational college students' internship evaluation and the evaluation indexes include whether the diary and summary are timely submitted according to teachers' requirement, whether the internship record is complete, whether various contents of internship summary are truly realized, and whether the internship experience comes from the heart. As one of the key link for vocational college students to implement quality evaluation, the practice defense mainly lets the vocational college students involved in internship tell their internship experience, the work they engage in the internship, main problems they meet, the solutions they proposes, and experiences in a face-to-face way after the students complete their internship. On this basis, the defense committee of this specialty will propose relevant problems to let students answer on the spot so as to check vocational college students' internship quality.

\section{Conclusion}

In conclusion, the internship for vocational college students in the specialty of architectural engineering technology plays a key role in improve vocational college students' professional quality. 
The vocational colleges shall adopt their advantages and avoid their weaknesses according to their actual situation to explore new methods of improving vocational college students' practice quality so as to avoid the trend of deviation between theory and practice, effectively improve their practical operation ability and let them further adapt to the requirement of employment units for vocational college architectural engineering talents.

\section{References}

[1] Zou Guanghua, Zhang Fengyan, Liu Kainan, Analysis on Problems Influencing College Students' Graduation Practice Quality and Corresponding Countermeasures, Meitan Higher Education, 2009 (4).

[2] Ma Xiao'e, Reform and Exploration on Improving College Students' Graduation Practice Quality, Science \& Technology Information, 2009 (23).

[3] Sun Chunling: Analysis on Problems Existing in Vocational College Post Practice and Countermeasures, Science and Technology Innovation Herald, 2012 (3).

[4] Tong Weijun, Fan Yiyu: Systematic Design of Vocational College Post Practice, China Higher Education Research, 2012 (6).

[5] Peng Yongtao, Research and Practice on Post Internship Quality Evaluation Indexes of Vocational College Students in Specialty of Highway Engineering, Education for Chinese After-school, 2013 (18).

[6] Wang Dan, Xu Yinan, Mou Haixia, Mu Ran, Construction of Students' Internship Quality Evaluation System under Engineering Education, Journal of the Socialism Institute of Yunnan, 2014 (3). 